\title{
Chapter 2 \\ The Establishment of Catchment Management Agencies in South Africa with Reference to the Flussgebietsgemeinschaft Elbe: Some Practical Considerations
}

\author{
Richard Meissner, Sabine Stuart-Hill, and Zakariya Nakhooda
}

\begin{abstract}
The establishment of catchment management agencies goes beyond the involvement of governmental entities or the stipulations contained in regulatory structures and policies. A number of actors or stakeholders from both the governmental and non-governmental spheres are involved in establishing a CMA. Practices that are associated with CMA establishment often relate to personal experiences and the overall political landscape as well as administrative development trajectories. These are also context specific to the respective catchment. We reflect on some of the administrative processes as a way to discern noticeable practices in the establishment of CMAs. Our case study material is the South African CMA establishment process to date. Some of the practices that come out strongly are human resource issues and financial accounting practices that decision-makers need to consider when establishing CMAs. An appreciative relationship with key stakeholders, meeting them personally, is also crucial. The chapter is based on research commissioned and funded by South Africa's Water Research Commission between 2014 and 2016. The process of establishing the Flussgebietsgemeinschaft Elbe in Germany is also outlined to illustrate the similarities and differences in the experience of establishing a river basin organisation in a developed and developing country.
\end{abstract}

Keywords Catchment management agency - Administrative process • BreedeGouritz CMA • Inkomati-Usutu CMA • Lessons learnt

\footnotetext{
R. Meissner $(\square)$

Council for Scientific and Industrial Research, PO Box 395, Pretoria 0001, South Africa

Centre for Water Resources Research, University of KwaZulu-Natal,

Private bag X01, Scottsville 3209, South Africa

e-mail: Rmeissner@csir.co.za
}

S. Stuart-Hill • Z. Nakhooda

Centre for Water Resources Research, University of KwaZulu-Natal,

Private bag X01, Scottsville 3209, South Africa 


\subsection{Introduction}

The establishment of a river basin organisation like a catchment management agency (CMA) might seem like a straightforward process where structures of rule, such as government acts and policies, stipulate how and why such organisations need to be established. A perception like this can be deceiving, especially when one considers the role and involvement of various actors in the establishment process. The difficulty does not always arise in the interpretation of an act, but starts when one defines what governance and its purpose is, especially beyond management interventions and enforcement of law. For us governance is not only about government and legislation or the linear cause and effect constituted by causal mechanisms such as the drafting and promulgation of legislation. Governance is more complex and involves various feedback loops (e.g. Meissner and Jacobs 2014) in any governance endeavour. Governance takes place at multiple levels in society and through multiple processes. The multilevel pathways of governance are influenced by both institutionalised governance mechanisms, like regulations, and non-institutionalised mechanisms such as norms and principles (Meissner and Jacobs 2014). We define governance as (often non-harmonious) interactive socioeconomic and political forms of governing (Rhodes 1996; Meissner et al. 2013) between various non-state and state actors, including individuals, to create opportunities and solve problems (Kooiman et al. 2008) in society. To reiterate, during this governance process, both institutionalised and non-institutionalised mechanisms are at play.

We argue that multilevel governance is at the order of the day when considering the case of South Africa's CMA establishment process. The CMA establishment process dates back to the late 1990s when South Africa embarked on a reform process of its water legislation. Based on the participatory and open process of writing the White Paper on a National Water Policy for South Africa, the government designed and promulgated the National Water Act (No. 36 of 1998) in 1998. The act is explicit on the CMA establishment process, stating in exact terms how a CMA should be established, who should play what role and how the governing board of the organisation needs to be constituted (RSA 1998). Furthermore, the Guide to the National Water Act (DWAF n.d.) and the public document Water Management Institutions Overview (de la Harpe et al. n.d.) give more detailed definitions and guidelines that could assist the establishment process. Considering that governance is more than the activities emanating from government structures and legislative requirements, establishing an organisation like a CMA involves more than just government officials and the governing board of the CMA. Especially in the case of South Africa abolishing the old Water Act of 1956 (Union of South Africa 1956) and replacing it with a "new" act that embraces the right to water and well-being as laid out in the country's constitution and emphasises the elements of integrated water resource management (IWRM) in various ways (Stuart-Hill and Schulze 2010), the CMAs strongly represent social equity and transformation. Both these aspects are high on the political agenda in post-apartheid South Africa and by implication are linked to high expectations from water users. 
This chapter reflects on some of the institutional and non-institutional aspects of governance in establishing the country's CMAs. The first section of the chapter deals with the CMA establishment process thus far. In this section we briefly examine the process since the idea of CMAs was first mooted in the late 1990s. We then reflect on the practices that we had identified during the face-to-face interviews and stakeholder meetings we attended for the research project. We end with a discussion and conclusion in which we make a number of recommendations of key aspects for successful CMA establishment.

\subsection{Methodology}

This chapter draws on the results of a 2-year research project we are currently conducting for the Water Research Commission, entitled Lessons Learnt from the Establishment of Catchment Management Agencies (K5/2320). The research team has been working with the CMAs and in their respective water management areas for a number of years. Thus the results presented here are drawn not only from the current investigation and conversations but also from past experience and data gathered for other research endeavours (e.g. Meissner and Funke 2014; Stuart-Hill and Schulze 2015). The approach we followed for the Lessons Learnt project was to conduct face-to-face structured interviews with various stakeholders or role players involved in the establishment process or those that had been part of the process in the past. To date we have conducted interviews with 27 individuals and attended three stakeholder meetings in the Breede-Gouritz and the Inkomati-Usutu CMAs, ${ }^{1}$ as well as an interview with representatives of the Flussgebietsgemeinschaft Elbe (FGG Elbe) in Magdeburg, Germany. ${ }^{2}$ We conducted this interview to investigate the process followed by a developed country in establishing a river basin organisation. The inclusion of the FGG Elbe interview may seem ad hoc; however, the comparison with FGG Elbe identifies the similarities and differences in the experience of establishing a river basin organisation elsewhere in the world. There are important ontological differences between the South African CMAs and the FGG Elbe that could enable decision-makers in both realities to learn from one another's experiences. Some observers might be tempted to argue against the inclusion of the FGG Elbe in that we are comparing "apples with oranges", so to speak. Nevertheless, as pointed out by Lijphart (1971), John Stuart Mill developed a method of comparing differences. In this case, we used deliberate randomisation to select the cases we

\footnotetext{
${ }^{1}$ These CMAs were previously called the Breede-Overberg Catchment Management Agency and the Inkomati Catchment Management Agency. Their names have now changed, and we will refer to them by their new names throughout the text, unless we are looking at a significant process before their renaming.

${ }^{2}$ In July 2015 the lead author travelled to Hamburg, Germany, for a month-long research visit to investigate water security in Hamburg. This visit afforded the lead author the opportunity to visit the FGG Elbe, since Hamburg is a harbour city situated on the banks of the Elbe river.
} 
would like to compare, namely, the South African CMAs with the FGG Elbe, in that the river basin organisations are alike " ... with a very high degree of probability, but not with absolute certainty" (Lijphart 1971: 684) since they are all river basin organisations in different geographical and socio-political settings. The inclusion of the information gathered during the interview with the FGG Elbe representatives is not an end in itself, but an aid in the comparative method (Lijphart 1971) we are utilising to investigate the practical considerations in establishing CMAs in South Africa. Our argument is that this could provide a better understanding of the establishment of a river basin organisation in other parts of the world. The intention of the FGG Elbe interview was not to identify so-called best practices, but to gain a deeper understanding of motivations and context in establishing river basin organisations.

For the face-to-face interviews in South Africa, not only did we target individuals from the two existing CMAs, we also conducted interviews with government officials that are closely involved in the establishment of the remaining seven CMAs in South Africa, most notably, the Vaal CMA and Pongola-Umzimkulu CMA. The latter includes a lived experience from the current establishment phase through attendance of the steering committee meetings. During the interviews we asked stakeholders to reflect on the establishment process thus far. We also made a number of observations during the three stakeholder meetings. Through these observations we identified a number of processes that were deemed important by the interviewees for consideration in establishing the remaining CMAs. We then grouped the issues identified in the interviews into five categories, namely, structures of rule, not including stakeholders, finances and public administrative processes, the difference between the main and trading accounts of DWS and the management of stakeholder relations. Before discussing these practices, we will give a rendition, by way of a historical account, of the CMA establishment process to date.

\subsection{The CMA Establishment Process}

South Africa's existing CMAs were established in terms of section 78(1) of the National Water Act (Act No. 36 of 1998) (RSA 1998). One of the main principles of the National Water Act is its focus on decentralisation. Decentralisation places an emphasis on public participation in water management and related decision-making processes. Decentralisation also rests on the subsidiary principle, which is encapsulated in the South African Constitution (RSA 1996). Subsidiarity means that those functions that can be more effectively and efficiently carried out by lower levels of government should be delegated to the lowest appropriate level (Funke et al. 2007; Meissner and Funke 2014). In this regard, the National Water Act and the Constitution are two structures of rule that are constitutive in the establishment of CMAs. Nevertheless, they are not the only causal mechanisms in establishing CMAs.

In October 1999, the government of South Africa established 19 water management areas (WMAs). The boundaries of these areas are along catchment divides and 
do not coincide with the administrative boundaries of local and provincial government spheres. At that time, the government contemplated the establishment of 19 CMAs (Meissner and Funke 2014), one in each WMA. Since the promulgation of the National Water Act in 1998, the implementation of the legislation has been slow and problematic (Funke et al. 2007; Meissner and Funke 2014). These implementation problems also translated in the slow implementation of the envisaged 19 CMAs (Hattingh et al. 2004; Meissner and Funke 2014), with only two CMAs implemented to date, namely, the Breede-Gouritz and the InkomatiUsutu CMAs. In 2012, the Department of Water and Sanitation (DWS) decided to reduce the 19 planned CMAs to nine; the minister approved the establishment of nine CMAs in the newly delineated nine WMAs. This move was due to a reconsideration of the management model and viability assessments related to water resource management, funding, capacity, skills and expertise in regulation and oversight. The decision was also an attempt to improve integrated water resource management. The nine CMAs are Limpopo, Olifants (Mpumalanga Province), Inkomati-Usutu, Pongola-Umzimkulu, Vaal, Orange, Mzimvubu-Tsitsikamma, Breede-Gouritz and Berg-Olifants (Western Cape) (DWA 2013). Currently and apart from the BreedeGouritz and Inkomati-Usutu CMAs, the remaining seven CMAs are considered the so-called proto-CMAs since they are in the process of being established. Those proto-CMAs are managed by the respective regional offices of the DWS.

Thus, prior to the establishment of the Breede-Gouritz and Inkomati-Usutu CMAs, management of the water resources of the two catchments was the responsibility of the DWS regional offices in the Western Cape and Mpumalanga Provinces, respectively. Water management took place through the water management area's internal strategic perspective (DWAF 2004). In the case of the FGG Elbe, it was established to coordinate the implementation of the European Union's Water Framework Directive of 2000 and the Floods Directive of 2007 for Germany's federal states sharing the Elbe river basin. Prior to the establishment of the FGG Elbe, the German federal states sharing the Elbe river managed it in terms of Germany's national legislative framework. ${ }^{3}$

The CMAs will perform certain water management functions and are required to cooperate and seek agreement on water-related matters amongst various stakeholders and interested parties. In essence, CMAs are service delivery agencies and are listed in the Public Finance Management Act, 1999 (Act No. 1 of 1999). The CMAs are also linked to Treasury Regulations to ensure financial viability and good governance (DWA 2013). Catchment management agencies also have a mandate to develop a catchment management strategy. This strategy is a plan to "realise the protection, use, development, conservation, management and control of water resources in [a CMA's] respective WMA" (Meissner and Funke 2014: 185; DWAF 2004; Funke et al. 2007). The catchment management strategy therefore gives effect to the role and functions of a CMA. Various stakeholders were involved in the establishment of both the above-mentioned South African CMAs and followed a negotiation process guided by the regional offices of the Department of Water and Sanitation

${ }^{3}$ Personal communication, Sandra Naumann, FGG Elbe, 10 July 2015 
$(\text { DWS })^{4}$ (McConkey et al. 2005). In the case of the Breede-Gouritz and InkomatiUsutu CMAs, a reference group was established, consisting of representatives from various sectors, such as agriculture, local government, emerging farmers and the tourism industry. The DWS was the most notable stakeholder assisted by private consultants $^{5}$ (Meissner and Funke 2014). These consultants assisted in the preparation of discussion documents and facilitation of meetings and focused on the interaction with role players around concerns and suggestions of stakeholders in their specific regions (MBB Consulting 2001). In the case of the FGG Elbe, ten German federal states were involved in its establishment. These federal states all share the Elbe river basin. Germany's Federal Ministry of the Environment was also involved in the establishment process. There is a similarity between the CMA's catchment management strategies and the FGG Elbe river basin management plan, in that in both cases the organisations had to develop their own river basin management plans. ${ }^{6}$

The original impetus for the establishment of the FGG Elbe was government or supranational (European Union) structures of rule or two European Union directives. It would appear that in the South African cases, the process, after government direction, viz. South Africa's National Water Act, was more decentralised with the involvement of various stakeholders from society and government. This was in line with the decentralisation vision set by the South African government in the post1994 political dispensation, which favoured more involvement of organisations at grassroots level as opposed to the command-and-control vision of pre-1994 governments. From this discussion on the history of the CMAs and the FGG Elbe's establishment process, it is clear that governments or supra-governmental entities drove the process. When observing the history of CMA establishment from a macroperspective (i.e. a process conducted and directed by government), hidden causal mechanisms at play can easily be ignored by observers. These hidden variables came to the fore during the interviews we conducted with the various stakeholders in South Africa and to a certain extent in Germany. The next section reports on these practices at play.

\subsection{Stakeholders' Discernible Practices}

Alluding to the brief description of the river basin organisations' establishment process, we can identify a number of practices. The first of these relates to the structures of rule mentioned above. The National Water Act is central to the CMAs in

\footnotetext{
${ }^{4}$ Between 1994 and 2009, this department was known as the Department of Water Affairs and Forestry (DWAF) and between 2009 and May 2014 as the Department of Water Affairs (DWA). It is currently referred to as the Department of Water and Sanitation (DWS) (Meissner and Funke 2014).

${ }^{5}$ Personal communication, Derek Weston, Pegasys Consulting, 12 September 2012

${ }^{6}$ Personal communication, Sandra Naumann, FGG Elbe, 10 July 2015
} 
that it gives the Minister of Water and Sanitation a strong influence to appoint the CMA's governing board. The governing board is to be the representative of all stakeholders within the WMA. Even so, the CMAs are at the same time quite autonomous and have mechanisms of democratic control, e.g. the establishment of relationships with similar organisations in other countries. The required CMS for each WMA and CMA also sets principles for water allocation and considers issues related to water resource protection, use, development, conservation, management and control. In the case of South Africa, these measures must be in line with the National Water Resource Strategy (Meissner and Funke 2014). However, a CMS is yet to be drafted for either of the established CMAs. This is largely due to the incorporation of other WMAs with the current CMAs. ${ }^{7,8}$ For instance, the BreedeOverberg WMA had been amalgamated with the Gouritz WMA. In the case of the Gouritz CMA, establishment of the CMA was put on hold until the amalgamation of the WMAs was completed. When the FGG Elbe implemented the Water Framework Directive, significant water management issues had been derived by the federal states at a river basin level such as river continuity, nutrient loads and chemical pollution, pollution from old industrial areas in the former German Democratic Republic (GDR), climate change and geomorphology in the river basin. These issues make the management of the Elbe river a constant challenge confirmed by representative from the FGG Elbe. ${ }^{9}$ This is something that South Africa's CMAs should expect when their strategies are implemented even when they are well established and functioning; everything could be a constant challenge because of pressures from various sectors and the CMAs will have to manage a complex natural resource system with the aim of socio-economic development.

Secondly, when it comes to the involvement of various stakeholders, the results of previous research studies conducted on the Breede-Overberg CMA have indicated that it is not always feasible to include all stakeholders in a water management area in the development of the CMS. This is one of the major hidden variables in the establishment of a CMA. The sheer number of people that want to attend meetings can draw out the process unnecessarily and make it time-consuming ${ }^{10}$ (Meissner and Funke 2014). The same applies to the Inkomati-Usutu CMA, where a series of five stakeholder meetings and workshops were held by the CMA over the period of a year (2010), specifically around the development of a CMS (Nyakane-Maluka and Jackson 2010). This has had a direct impact on the financial and human resource costs of establishing the agency. The question of involving a large number of stakeholders was an issue that also came up during interviews at the FGG Elbe. In this case, the officials explained that due to the involvement of ten different federal gov-

\footnotetext{
${ }^{7}$ Personal communication, Johann Boshoff, Inkomati-Usuthu Catchment Management Agency, 23 June 2015

${ }^{8}$ Personal communication, Phakamani Buthelezi, Breede-Gouritz Catchment Management Agency, 24 August 2015

${ }^{9}$ Personal communication, Sandra Naumann, FGG Elbe, 10 July 2015

${ }^{10}$ Personal communication, Derek Weston, Pegasys Consulting, 12 September 2012
} 
ernments, assortment of economic and political interests and aims in the management of the Elbe river came to the fore and had to be negotiated. They also had different structures of rule influencing, for instance, the monitoring of river health. This can lead to a long and time-consuming process to reach agreement on certain issues. ${ }^{11}$

In terms of financial and human resources, establishing a CMA can be a demanding and taxing process from a public administrative perspective. This is the third practice that has emerged from the interviews. Regarding human resources, for instance, the process can require a large number of consultations with employees from the government department that need to be transferred to the CMA once it has been established. One issue that needs consideration is that the offices of the CMA might not be located near the regional or national offices of the DWS. This means that employees that had been travelling to the regional and/or national office(s) now might need to relocate to a different town so they can be closer to their place of employment. This is the case with the Vaal proto-CMA currently being established, which might be situated near Rand Water's head office to the south of Johannesburg. To transfer employees from the DWS offices in Pretoria will further involve labour relation matters. ${ }^{12}$ Some employees might feel that they do not want to be transferred because of personal reasons. This will involve the negotiation of transfer policies not only at individual level, but labour unions also need to be involved. It is likely that this may lead to resistance from employees and low morale because they are uncertain about the implications of such human resource practices. This process therefore needs careful management and will have to be conducted in a thoroughly transparent manner.

On a separate note, transfer agreements will involve matters such as employees' pension funds, medical aid, salaries and salary levels, systems for salary payments, labour union representation, leave management and so on. In addition to the administrative processes involved regarding human resources, employees' perceptions around uncertainties regarding employment security must also be taken into account. ${ }^{13}$ Change management therefore becomes an important process in the establishment of a CMA.

Fourthly, the difference between a trading entity and the main account of the DWS needs to be considered. This is a distinctly South African matter. A trading entity is funded from water users that pay for the water they consume, like irrigation boards. Department staff members of such trading entities are paid salaries from the trading account. The main account is the funding or budget that the DWS receives from National Treasury. The challenge with this difference is that corporate management of the DWS, excluding finance, has been servicing both accounts and the accounts of the staff members that might be transferred had also been serviced from both accounts. One way of getting around this administrative issue is by seconding people to the CMA once it has been established; that will give added support to the CMA when it is operating sustainably. Another challenge is that hydrometry

\footnotetext{
${ }^{11}$ Personal communication, Sandra Naumann, FGG Elbe, 10 July 2015

${ }^{12}$ Personal communication, Sydney Nevhorwa, Department of Water and Sanitation, 10 June 2015

${ }^{13}$ Personal communication, Sydney Nevhorwa, Department of Water and Sanitation, 10 June 2015
} 
services might also move to the CMA from the main to the trading account. This will also be the case for water use and regulation where budgets need to be transferred in the same way. The issue with this is that the functions of these units are linked to the type of account and moving the units will have human resource implications. For instance, service-level agreements need to be in place between the CMA and the regional and national offices so that the services to be supplied by the DWS and/or CMA need to be well defined and stipulated. ${ }^{14}$

Effective management of stakeholder relations is another important component of CMAs, and this is the fifth practice identified by the authors. We also observed this practice when interviewing the representatives of the FGG Elbe. For the FGG Elbe, stakeholder relations are not only an important communication endeavour (e.g. keeping stakeholders abreast of what is happening in the river basin and flood warning) but also necessary in the daily functions like river health monitoring. ${ }^{15} \mathrm{We}$ argue that without good stakeholder relations, decentralisation cannot be adequately achieved since decentralisation involves the interface (e.g. communication) between authorities and stakeholders at grassroots level. In this regard, both established CMAs have relatively close and remarkably good relationships with stakeholders. These relationships, as with any relationship, had to be built from the onset. For instance, initially, stakeholders were reluctant to engage with the Breede-Gouritz CMA owing largely to challenging experiences with the regional/national DWS offices. For instance, some individuals in stakeholder groupings have been waiting on DWS for numerous years with regard to licencing applications. ${ }^{16}$ Because of this matter, stakeholders wanted to know whether the CMA would be any different from the way in which DWS carries out water-related activities and tasks. In other words, there is an expectation from stakeholders that the CMA will, in certain instances, do a "better job" than the DWS. The onus was on CMA staff attending the meetings to persuade the stakeholders firstly to participate in stakeholder meetings and explain the benefits of these meetings and secondly to give members the assurance that the past is the past and that the CMA would have other options at hand to assist stakeholders with their needs. ${ }^{17}$

\subsection{Conclusion and Recommendations}

The establishment of a CMA does not happen overnight. There are a number of issues that need to be considered by policy-makers and stakeholders involved in the establishment process. Structures of rule are important constitutive aspects in the

\footnotetext{
${ }^{14}$ Personal communication, Sydney Nevhorwa, Department of Water and Sanitation, 10 June 2015

${ }^{15}$ Personal communication, Sandra Naumann, FGG Elbe, 10 July 2015

${ }^{16}$ Attendance of a stakeholder meeting with the Breede-Gouritz Catchment Management Agency staff, 20 August 2015

${ }^{17}$ Attendance of a stakeholder meeting with the Breede-Gouritz Catchment Management Agency staff, 20 August 2015
} 
establishment of a river basin organisation. We have seen this in the case of South Africa's CMAs and the FGG Elbe. Nevertheless, structures of rule are not enough. There are other variables also at play in the establishment of river basin organisations and their subsequent governance. Variables that are important in this regard are the involvement of stakeholders during the pre-establishment phase and stakeholder relations after establishment. These are important aspects which require careful management in order for the CMAs to achieve their objectives of decentralised, participatory, sustainable water resource management.

The sheer number of stakeholders involved during the pre-establishment phase was an issue not only for South Africa's CMAs but also for the FGG Elbe. It became a complex affair in both cases because stakeholders bring with them their own issues, perceptions, expectations and interests. With regard to the financial aspects of CMAs' operations, there are no issues currently, but for future development of the CMA, this may be a constraint. The DWS should continue to provide financial support to the CMA even after the CMA starts receiving water tariffs. This would not only highlight the support of the DWS of a decentralised approach to water resource management, but will also enhance staff morale and give the CMA the ability to carry out an even wider range of tasks in developing water resources sustainably. There is also a need for participatory management as well as implementing the vision of equity in water resource management and the achievement of water security, which would further enable the CMA to play its role as catchment steward. The DWS could also consider phasing out such financial support; at this stage it is impossible to reach a definite conclusion as to what the results of this action might be, since there is no past experience of this in South Africa. It would therefore be premature to say that it could jeopardise the financial viability of the CMAs.

Currently, stakeholder relations between the CMA and members within the WMA are relatively good in the two established and operational CMAs. This is also the case with the FGG Elbe where they keep stakeholders abreast of current affairs in the Elbe river basin. It would appear that the CMAs and the FGG Elbe have put a high premium on stakeholder relations. This is something that will stand these organisations in good stead for their future governance endeavours. However, in the case of CMAs, there is room for improvement when it comes to perceptions regarding the involvement of DWS in the establishment process. Trustworthy and constructive stakeholder relationships are central to the effective and efficient management of water resources and to an extent the success of CMAs. From current observations of several stakeholder meetings, we observed that DWS officials often arrive late for these meetings and failed to cater to the needs of attendees, therefore adding to the negative perceptions of the DWS. What is more, language can be a barrier since people, especially those in the rural areas, are more comfortable getting and delivering messages in their native language. This is something the CMAs also need to consider.

Furthermore, currently the CMAs have an adequate staff complement. Nevertheless, adequate does not mean that there are no shortages. Certain areas, such as water quality monitoring, require sufficient technical staff. This seems to be an issue at the Inkomati-Usutu CMA as they outsource the testing of their water 
samples. Sample testing has a very long turnaround time due to issues with the laboratory. If the CMA had its own functioning laboratory, test results would be obtained a lot faster, and more water samples could be tested. However, the establishment and operation of a laboratory have its own logistical challenges, one of which is accreditation from applicable regulatory bodies like the South African National Accreditation System (SANAS); these factors should be carefully considered before making a decision regarding an independent laboratory.

Within the establishment phase of CMAs, DWS could provide more resources and guidelines with regard to the initial functions of CMAs. This could enable the CMAs to begin operations fully understanding their roles and responsibilities. A comprehensive list of initial functions, including processes and tools, beyond what is mentioned in the National Water Act of 1998 and possibly in the National Water Resource Strategy (DWA 2013), needs to be produced so that staff have an understanding and adequate guidance as to what is required of them. It would be advisable to include a staff member with a legislative background in the establishment and operational process. In order for the CMA to provide adequate monitoring and enforcement, individuals with an understanding of environmental law should be included as the CMA receives its full delegation. This was lacking with regard to the Inkomati-Usutu CMA as well as the Breede-Gouritz CMA. ${ }^{18}$ The establishment of a proto-CMA within DWS regional offices may be a good option. This would allow the CMA to "hit the ground running" as opposed to taking time to find its feet. However, this also has the risk of "copying and pasting" activities and decisionmaking processes from the regional DWS office. As alluded to above, this is not adequate to fulfil functions and establish relationships with stakeholders.

A clear direction between national strategic initiatives, structures of rule and the management of the river basin at WMA and basin levels assists policy-makers involved in the establishment process on what needs to be done and gives a clear direction on how to initiate the process. This includes clarity on functions, roles and responsibilities. There seems to be very little space for ambiguity, and uncertainty has a significant impact on the success of the establishment phase, which can carry through into the operational phase. Not only is there uncertainty during the establishment phase. In the case of the FGG Elbe, the representatives said that they are constantly being challenged by issues such as pollution and nutrient loads. This is likely to also be the case with South Africa's CMAs since they are also, like the FGG Elbe, managing a complex natural resource with multiple stakeholders.

Moreover, officials need to plan the establishment process very carefully, especially regarding the allocation of financial and human resources. Careful planning would enable policy-makers to ascertain where to draw the line when involving a certain number of stakeholders and can assist them in striking a balance between involving too few or too many stakeholders. With regard to financial resources, both CMAs currently receive sufficient funding from DWS. However, as the CMAs have now become large spatial units with numerous catchments and sub-catchments,

${ }^{18}$ Personal communication, J Boshoff, Inkomati-Usutu Catchment Management Agency, 23 June 2015 
with further delegations, the allocation of financial resources may become a future issue. Also, it is envisaged that CMAs will become self-sufficient, thereby attaining funds through receiving tariffs paid by water users. This could prove to be a major financial constraint as the CMA would receive approximately $70 \%$ of its expected budget through these tariffs. There are still questions with regard to the remaining $30 \% .{ }^{19}$ Planning the financial viability and security of the CMA becomes a key variable here, and sufficient finances need to be allocated to enable the CMAs to ensure their ability to be responsive to the administrative and stakeholder demands.

Regarding human resource processes, it is recommended that labour unions be involved from the outset so that uncertainties can be minimised and employees can take ownership of their transfers. Another issue with regard to the employment of staff is that there is no task-specific training of individuals. All conversations, interviews and engagements have shown that the CMA environment requires a different set of skills compared to the known job profiles of regional or the national DWS officials. This means that the majority of the tasks carried out by the CMA require staff to learn as they grow within the CMA environment. ${ }^{20,21}$ Such learning needs an adaptive, responsive organisational set-up and a leadership that trusts its employees and vice versa. It is not our intention to impose adaptive management principles on the organisation. However, it should be clearly stated that the learning environment of the organisation should not be restricted to a set of lawlike principles; the organisation's leadership needs to decide how it will apply learning practices. Should adaptive management principles be imposed on an organisation, it would mean that command and control had moved from an old centralised government authority to an unaccountable and centralised "epistemic authority". The employees should be given the space and possible training to enable engagement and learning in a continuous and inclusive manner.

What is more, future CMAs would have to take note of stakeholder expectations, and those expectations should be partially defining in establishing a relationship between the CMA and its stakeholders. These issues or practices might not be major constraints, but could influence the operations of a CMA and thus its successes significantly.

Policy-makers should also bear in mind that the establishment process is not only about pitfalls and challenges. There are also opportunities to take advantage of. One such opportunity is the knowledge of public administrative processes held by DWS officials. Such knowledge can be a defining resource between a successful and stalled establishment process. In this regard, the knowledge of public administrators should not be viewed by stakeholders, scientists included, as another burden on the establishment process. Scientists have a tendency to not include public administrative

\footnotetext{
${ }^{19}$ Personal communication, Jan van Staden, Breede-Gouritz Catchment Management Agency, 25 August 2015

${ }^{20}$ Personal communication, Johann Boshoff, Inkomati-Usutu Catchment Management Agency, 23 June 2015

${ }^{21}$ Personal communication, Phakamani Buthelezi, Breede-Gouritz Catchment Management Agency, 24 August 2015
} 
processes in their research endeavours when analysing CMAs. They would rather look at the streamlining of the establishment process, technical skills and possibly political issues. The identified practices and conclusions drawn should therefore not be seen as a set of recommendations for policy-makers and stakeholders involved in CMA establishment processes only, but also for scientists researching the process. Scientists are, after all, also stakeholders when they research CMAs and may also be involved in some of the CMAs currently being established. The research has shown a strong link between the successes or challenges of the establishment process and the way in which CMAs operate. This is an area where further research is needed as the process of establishing the other seven CMAs progresses.

\section{References}

De la Harpe, J., Ferreira, J. -A., \& Potter, A. (n.d.) Water management institutions overview. Pretoria: Department of Water Affairs and Forestry.

Department of Water Affairs (DWA). (2013). National water resource strategy, June 2013 (NWRS 2nd ed.). Pretoria: Department of Water Affairs.

Department of Water Affairs and Forestry (DWAF). (n.d.) Guide to the National Water Act. Pretoria: Department of Water Affairs and Forestry.

Department of Water Affairs and Forestry (DWAF). (2004). National water resource strategy. Pretoria: Department of Water Affairs and Forestry.

Funke, N., Nortje, K., Findlater, K., Burns, M., Turton, A., Weaver, A., \& Hattingh, H. (2007). Redressing inequality: South Africa's new water policy. Environment, 49(3), 10-23.

Hattingh, J., Maree, G., Oelofse, G., Turton, S., \& Van Wyk, E. (2004). Environmental governance and equity in a democratic South Africa. Conference paper presented at the AWRA/IWLRI International Conference on Water Law Governance in Dundee, Scotland.

Kooiman, J., Bavinck, M., Chuenpagdee, R., Mahon, R., \& Pullin, R. (2008). Interactive governance and governability: An introduction. Journal of Transdisciplinary Environmental Studies, $7(1), 1-11$.

Lijphart, A. (1971). Comparative politics and the comparative method. The American Political Science Review, 65(3), 682-693.

MBB Consulting Engineers. (2001). Proposal for the establishment of a catchment management agency for the Inkomati Basin. Prepared on behalf of the Inkomati catchment management agency reference group. Department of Water Affairs and Forestry, Nelspruit, South Africa.

McConkey, G. E., Enright, W. D., Roberts, J. A., \& Khan, R. (2005). The development of a catchment management agency for the Breede River, Western Cape, South Africa. Cape Town: Department of Water Affairs and Forestry.

Meissner, R., \& Funke, N. (2014). The politics of establishing catchment management agencies in South Africa: The case of the Breede-Overberg Catchment Management Agency. In D. Huitema \& S. Meijerink (Eds.), The politics of river basin organisations: Coalitions, institutional design choices and consequences. Cheltenham: Edward Elgar Publishing.

Meissner, R., \& Jacobs, I. (2014). Theorising complex water governance in Africa: The case of the proposed Epupa Dam on the Kunene River. International Environmental Agreements:P, 14(2), $1-28$.

Meissner, R., Funke, N., Nienaber, S., \& Ntombela, C. (2013). The status quo of research on South Africa's water resources management institutions. Water SA, 39(5), 721-731.

Nyakane-Maluka, N., \& Jackson, B. (2010). The 2011/12 to 2013/14 strategic plan for the Inkomati Catchment Management Agency. Presentation to the Parliamentary Portfolio Committee, 8 June 2010, Cape Town. 
Republic of South Africa (RSA). (1996). Constitution of the Republic of South Africa (Act No. 108). Government Printer, Pretoria.

Republic of South Africa (RSA). (1998). National Water Act (Act No. 36). Government Printer, Pretoria.

Rhodes, R. A. W. (1996). The new governance: Governing without government. Political Studies, XLIV, 652-667.

Stuart-Hill, S. I., \& Schulze, R. (2010). Does South Africa's water law and policy allow for climate change adaptation? Climate and Development, 2, 128-144.

Stuart-Hill, S. I., \& Schulze, R. (Eds.). (2015). Developing water related climate change adaptation options to support implementation of policy and strategies for 'Water for Growth and Development' (WRC report no. 1965/1/15). Pretoria: Water Research Commission.

Union of South Africa. (1956). Water Act No. 54 of 1956. Government Printer, Pretoria.

Open Access This chapter is distributed under the terms of the Creative Commons AttributionNoncommercial 2.5 License (http://creativecommons.org/licenses/by-nc/2.5/) which permits any noncommercial use, distribution, and reproduction in any medium, provided the original author(s) and source are credited.

The images or other third party material in this chapter are included in the work's Creative Commons license, unless indicated otherwise in the credit line; if such material is not included in the work's Creative Commons license and the respective action is not permitted by statutory regulation, users will need to obtain permission from the license holder to duplicate, adapt or reproduce the material. 